\title{
Intelligibility alterations in an oral cancer patient following primary surgery and
two reconstructions: A case study
}

\author{
Marlene Carno Jacobson BA (Sp \& H Therapy) (Witwatersrand) \\ Department of Speech Therapy and Audiology, \\ Hillbrow Hospital, Johannesburg
}

\begin{abstract}
Intelligibility and perceptual characteristics were examined in a bilingual Zulu/Xhosa-speaking patient following glossectomy: and mandibulectomy with primary closure and two subsequent reconstructions using osteomyocutaneous flaps. Changes across and fiberoptic investigations. Findings emphasise the need for reconstructive suro native speakers, lateral view xeroradiography, bility, relationships between articulators and the positioning of vocal tract constrictions. terious to speech and a more influential role for the speech therapist are discussed. The possibility of atrophic changes dele-
\end{abstract}

\section{OPSOMMING} sluit. Veranderinge in die verstaanbaarheid van die proefpersoon is oor in staanbaarheidstoetse (moedertaal luisteraars), laterale aansoon is oor in twaalf maande periode ondersoek. Daar is van vervindinge beklemtoon die noodsaaklikheid dat rekonstruktiowe xhiruagrografie en fiberoptiese ondersoeke gebruik gemaak. Betors en die posisionering van vernouings die traktus vokalis behou. Die artikulatoriese mobiliteit, verhoudings tussen artikulabeinvloed, word ook bespreek. ' $n$ Groter rol word vir die spraakterapeut in dikheid dat atrofiese veranderinge spraak negatief

The role of the South African speech therapist in the management of the surgically' treated cancer patient has been almost exclusively limited to the laryngectomee despite the comparable incidence of glossectomy and other shared features such as difficulties with communication. Among Sowetan Blacks, the ratio of larynx to tongue lesions is in the order of $3: 2,{ }^{8}$ a proportion closely corresponding to that noted in the United States of América. ${ }^{20}$

The primary objective of oral ablative surgery is curative. Hence excision of extensive tumours of the floor of the mouth, for example, may be forced to include resection of unaffected adjacent structures such as mandible, tonsil and anterior immediate well as associated cervical lymph nodes. Without Gump" (chinless) defortion, this may result in the typical "Andy ample (chinless) deformity "which is the most extreme extifiable by the oral crippling." 22 Such a case is readily idendeglutition his altered speech, disordered masticatory and cosmetic mechanisms, drooling, dental malocclusion and tion of a deformity. "The quality of life after successful ablacure rates." 22 .

Following primary excision of the tumour, it lies within the doadapt form and fuck reconstructive techniques to restore and The timing of function to the oral peripheral mechanism. Die Suid-Afrikanse cavity reconstructive surgery has been conDie Suid-Afrikaanse Tydskrif vir Kommunikasieafwykings, Vol. 30,1983
() SASHA 1983 troversial, but currently the compelling advantages of immediate rather than delayed reconstruction are being emphasised. The introduction of composite osteomyocutaneous and myocutaneous flaps (pedicled grafts containing a donor blood vessel and the associated skin, underlying muscle and sometimes bone) has stirred a new wave of enthusiasm for reconstructive surgery.

For the patient, the quality of life following radical surgery is largely a measure of adequate reconstruction ${ }^{17}$ "and the only thing that tends to tide the affected individual over the twilight zone is the hope that some day in the not too distant future, his somatic deformity will be corrected."

Published studies to date focus on speech following primary surgery only, i.e. without reconstruction.1. 2. II. ${ }^{14}$ One study explores the effects of a prosthetic tongue on intelligibility and
food management. ${ }^{13}$

At present, the focus of surgical reconstruction appears to highlight the anatomical parameters of tissue survival, its form, bulk and contour, with a comparatively diluted emphasis on functional integrity. It seems that the effects of various reconstructive procedures, remain largely
unexplored.

The present study was designed to elucidate the surgicallyinduced changes in articulator mobility, perceptual 
characteristics and composite speech intelligibility in an oral cancer patient who underwent an initial resection with primary closure, followed by two reconstructions, using osteomyocutaneous flaps. Whereas current surgical practice tends to resect and reconstruct within a single lengthy operation, the subject of this study underwent staged management and thereby afforded a unique opportunity for investigation.

\section{METHODOLOGY}

\section{SUBJECT}

T.N. was a fifty-six year-old Black bilingual Zulu/Xhosaspeaking illiterate male who underwent a suprahyoid block dissection (commando procedure) for a well-differentiated squamous carcinoma of the anterior floor of the mouth, in April, 1981. He was a heavy smoker and took alcohol frequently. The histopathology report described a $5 \times 1 \mathrm{~cm}$ lesion of the floor of the mouth anterior to the tongue, involving the base of the tongue and the gingiva. The cortex of the mandible had been invaded but no infiltration of the bone was observed.

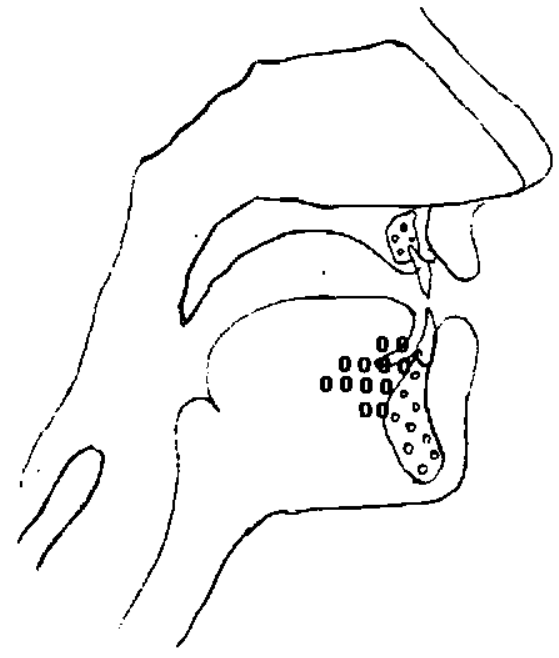

(a)

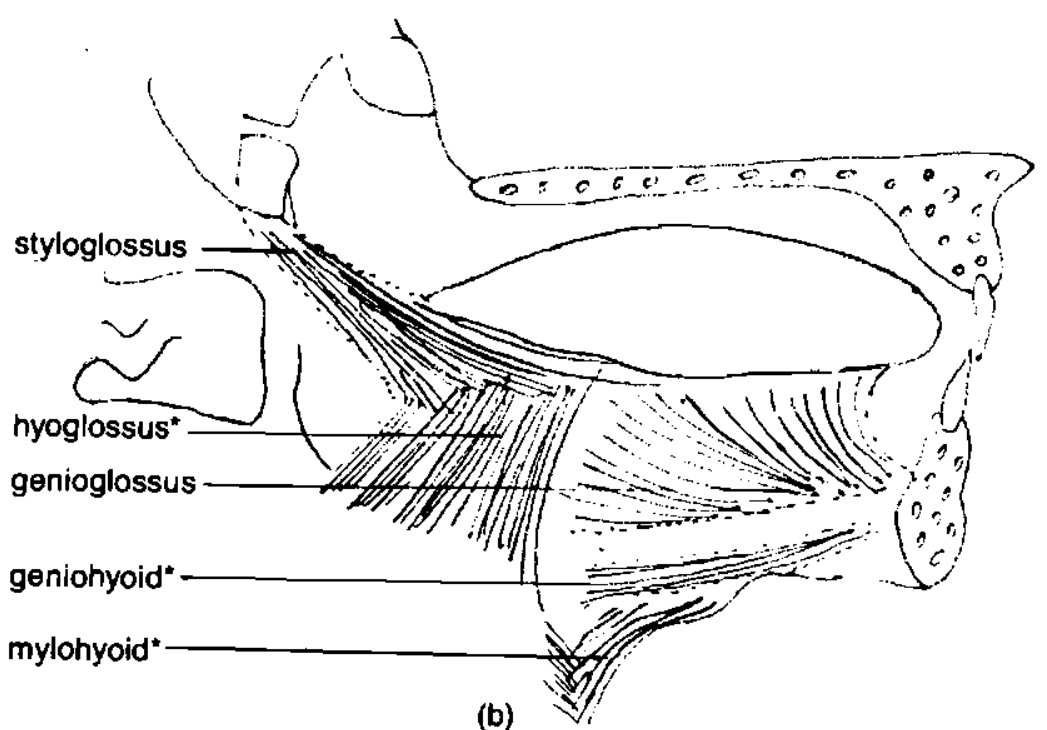

(b)

Figure 1 Anatomical details of site-of-lesion and primary surgery

(a) Lateral view of site and extent of tumour.

(b) Muscles (") divided during tumour excision.

(c) Frontal view of area of excision.

(d) Lateral view of area of mandibular excision.

\section{PRIMARY SURGERY}

Surgical excision included the resection of both mandibular rami from angle to angle, transection of the anterior half of the tongue, and removal of the floor of the mouth. Primary closure was achieved by attaching the remnant of the tongue bilaterally and anteriorly to the buccal mucosa. The geniohyoid, mylohyoid, and hyoglossus muscles were divided. The Hypoglossal nerve (XII) was preserved, but the mandibular branches of the Trigeminal nerve (V) were obligatorily severed, causing a loss of sensation in the lower lip.

Details of the original lesion and primary surgery are illustrated in Figure 1.

In September, 1981, the patient was admitted to the Hillbrow Hospital, Johannesburg, for reconstructive surgery. It was at this point that the writer first came into contact with him.

\section{SECONDARY SURGERY}

At this stage and three subsequent stages, the patient's speech was assessed using the procedures to be discussed shortly.

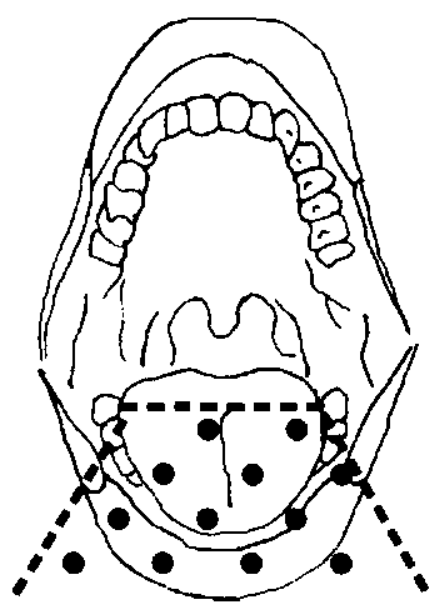

(c)

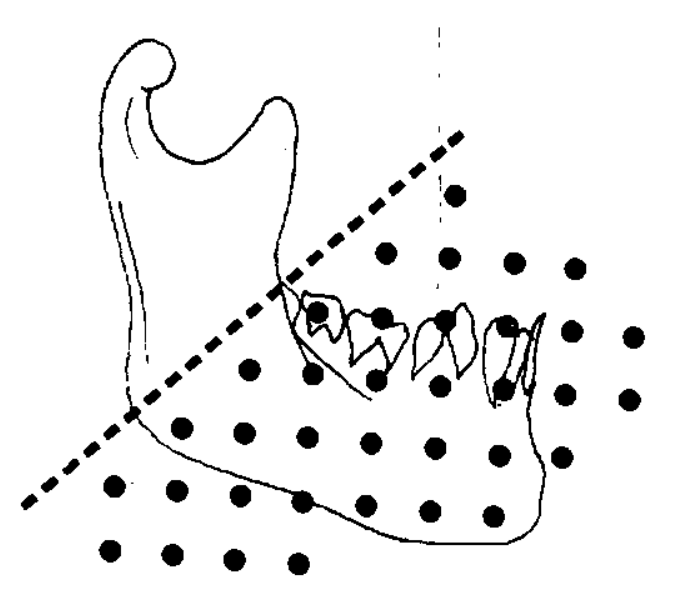

(d) 
These four stages co-incide with the pre- and post-reconstruction periods associated with each reconstruction. The first reconstruction, in October, 1981, employed a right pectoralis major (chest) osteomyocutaneous flap and the second, in June, 1982, a spine of scapula-trapezius (shoulder) osteomyocutaneous flap. The reason for the repeated attempt at reconstruction was the fact that resorption of the first graft occurred, leaving only a healthy skin island in the floor of mouth area.

Throughout the period subsequent to primary surgery (April, 1981, to August, 1982), T.N. experienced severe drooling owing to poor oral closure and dysphagia. Thus, vegetative functioning was poor at all four stages with only the swallowing of liquids and puréed foods being possible.

\section{PROCEDURES}

In order to explore and capture the speech changes comprehensively, a battery incorporating both subjective (1) and objective ( 2 and 3 ) procedures was utilised.

1. Speech intelligibility assessment: To obtain an index of intelligibility, an intelligibility task was constructed for administration to native speakers who were naive listeners.

2. Xeroradiographic studies: To obtain anatomical and physiological data regarding articulatory mobility and the variability of vocal tract dimensions. Xeroradiography provides excellent soft tissue definition; numerous soft tissue densities are presented in a single image, and the components of the speech production mechanism are easily identifiable by speech pathologists without radiographic training. ' 3. Fiberoptic examination: To examine altered anatomical
features.

(It should be noted that sound spectrography was used in order to derive an objective acoustic representation of auditory parameters. Data yielded by spectrographic measures are the subject of a further paper and will therefore not be discussed at present.)

\section{DATA COLLECTION}

\section{INTELLIGIBILITY DATA}

\section{Preliminary Speech Materrials}

At each of the four stages, the subject was required to imitate the model provided by a fluent Zulu speaker, of eightytwo Nguni words, extracted from an article by Lanham ${ }^{10}$ and an informal Zulu word list. These imitations were recorded on a Uher 4200 Report Stereo IC reel-to-reel tape recorder with careful VU meter monitoring within a sound-
treated environment.

2. Intelligibility Test Construction

From these recordings four intelligibility tests were con-
structed, whereby thirty of the original structed, whereby thirty of the original eighty-two items stance of each of the phonemes $9.10,23$ at least one inpresented in the Appendix. of the study, it is unfortunate Owing to the retrospective nature been incorporated in thate that certain phonemes had not therefore, the find in the original speech sample and click; voiced clicks (/ist, namely $/ \mathrm{xh} /$, an aspirated lateral $/ \mathbf{n h l} /, / \mathbf{n d l})$ and $/ \mathbf{k l} /$. Implem $/ \mathrm{gq} /$ and $/ \mathrm{gx} /)$; and the affricates tional frameworks of articulation of principles of tradi-

Die Suid-Afrikaanse Tydskrif vir Kommunikasieafwykings, Vol. 30,1983 "word initial, medial and final positions"6 was rejected due to the difficult segmentation of multisyllabic words and the common characteristic of vowels in initial and final position in Zulu lexical items. Therefore target phonemes were not localised to specific positions within words. It was also impossible to regulate retrospectively, factors such as word length, semantic complexity or conversational familiarity.

3. Tape Construction: Four tapes were constructed by copying each imitated word three times consecutively from a Revox High Fidelity reel-to-reel recorder onto a Uher 4200 Report Stereo IC reel-to-reel recorder. No interval was scheduled between the three identical imitations. The interstimulus interval between successive test items was five seconds. The four thirty-item sequences were varied and randomised using random numbers to avoid a "listlearning effect". 18

4. Judges: Three judges were chosen, the selection criteria being that they were native speakers of Zulu, had hearing within normal limits, and normal speech discrimination ability at conversational level (55dB HL) and $75 \mathrm{~dB}$ HL using C.I.D. W.22 P.B. word lists. They had had no previous contact with the patient, nor knowledge of the nature of his speech pathology. The same judges were employed for all four tapes in order to maintain "listener-level stability". I8 5. Playback Conditions: Testing was conducted individually, the judges being seated in a sound-treated room approximately 1,6 metres in the midline from a pair of Bang and Olaufsen speakers, through which the experimental tapes were presented. The sequence of tape presentation varied for each judge to counteract a possible familiarisation effect which could bias the findings by exaggerating the average intelligibility of the tape played last. After listening to the thrice-presented production of a particular word, each judge was required to imitate the subject's production and then to guess the word that he was saying. The judges' responses were recorded on a Sony Stereo Cassette Corder TC with VU meter monitoring for later transcription and
analysis.

ANATOMICAL AND PHYSIOLOGICAL DATA:

1. Xeroradiography was repeated at each stage with lateral views taken of the articulators in a rest position and during the sustained production of five Zulu cardinal vowels.

2. Fiberoptic examinations were performed prior to and following the second reconstruction, using a standard Olympus VF 4a Vocal Cords Fiberscope with a camera
attachment.

\section{DATA ANALYSIS}

\section{INTELLIGIBILITY TEST}

At each of the four stages, the number of words correctly recognised by each of the judges was scored and totalled. A mean percentage intelligibility was derived for each tape. The number of refusals was also computed. The judges' stimulus imitations were broadly transcribed. Vowel and consonant analyses of these were conducted, using broad distinctive features in order to highlight perceptual confusions and basic
trends in the data. 


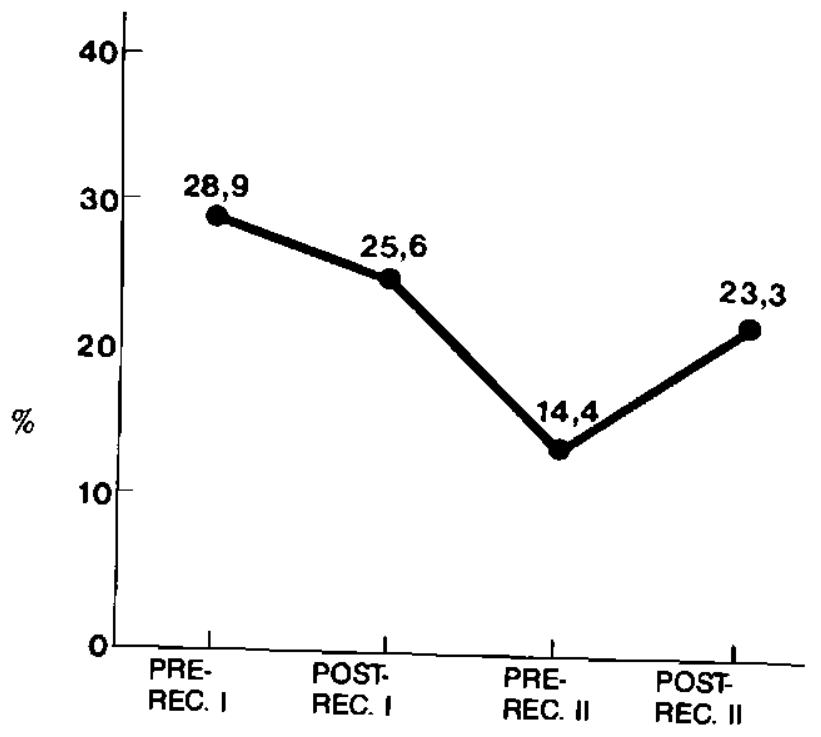

Figure 2 Percentage of words correctly recognised at each stage.

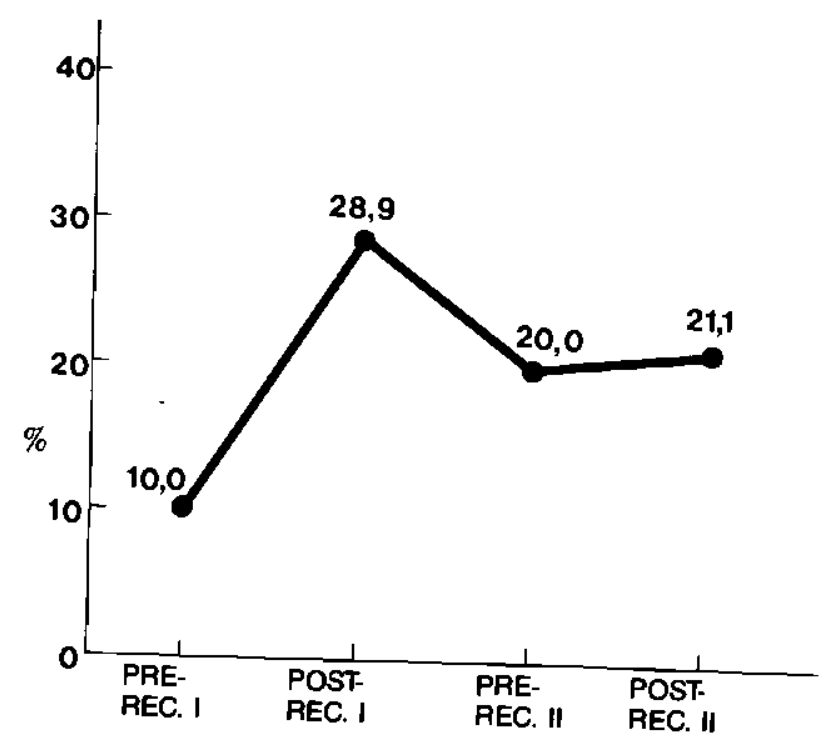

Figure 3 Percentage of words "refused" at each stage.

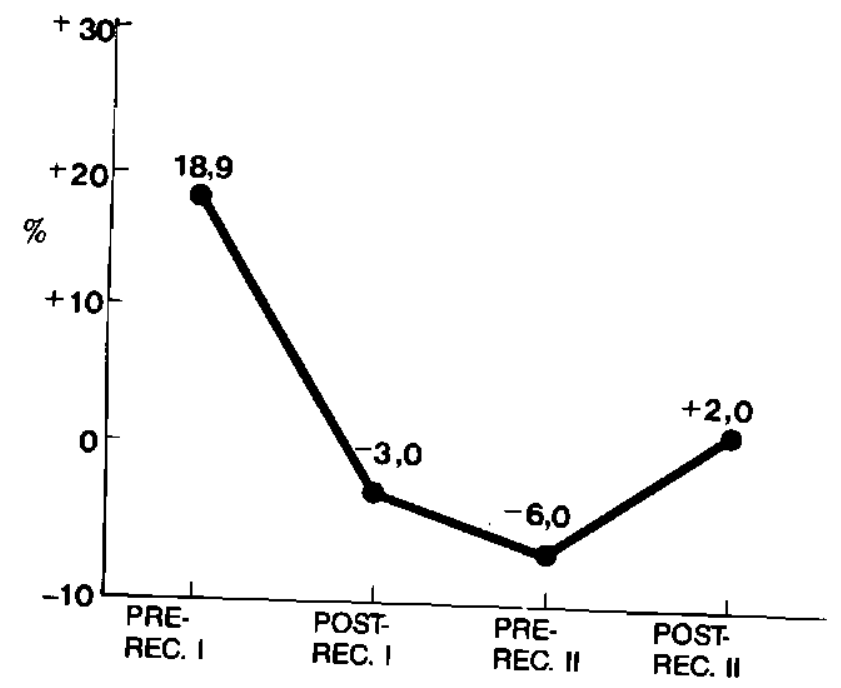

Figure 4 Percentage of correct words minus percentage of refusals at each stage.

\section{ANATOMICAL AND PHYSIOLOGICAL ASPECTS}

For each stage, superimposed tracings were done of the vocal tract configurations for the five vowels and the rest position, using the cervical spine as a constant axis. In this way, changes in vocal tract dimensions were illustrated.

\section{RESULTS}

\section{A. OVERALL SPEECH INTELLIGIBILITY.}

1. Single word intelligibility was greatest prior to any reconstructive procedure, that is, with contracted primary closure alone. This was a most surprising finding and contrary to expectation, as it suggested that reconstruction was functionally unconstructive and possibly destructive to speech (Fig. 2).

2. It may appear that the stage at which speech was almost as intelligible as pre-reconstruction speech was following the first reconstruction. However, notice the large number of refusals at this point (Fig. 3).

3. In order to magnify the differences between the various stages, the number of correctly guessed words was balanc- ed with the number of refusals by subtracting the latter from the former. Following this operation, it became apparent that the patient was considerably more intelligible prior to any reconstruction (Fig. 4).

4. Following the second reconstruction, speech was more intelligible than following the first, but still markedly inferior in comparison to pre-construction intelligibility (Fig. 4).

5. Note the deterioration in intelligibility occurring following the first reconstruction and prior to the second when graft resorption occurred (See Fig. 4). This feature is further elucidated by the xerographic findings.

\section{B (PHYSIOLOGICAL ASPECTS) (See Fig. 5) AND}

C (ANATOMICAL ASPECTS) (See Fig. 6)

1. If the tracings from each stage are compared, it is evident that prior to the first reconstruction, there was remarkable flexibility in the sizes of the oral and pharyngeal cavities with different vowel productions. (See Fig. 5a.)

2. Following the first reconstruction and prior to the second reconstruction, the "floor of the mouth" displays an in- 


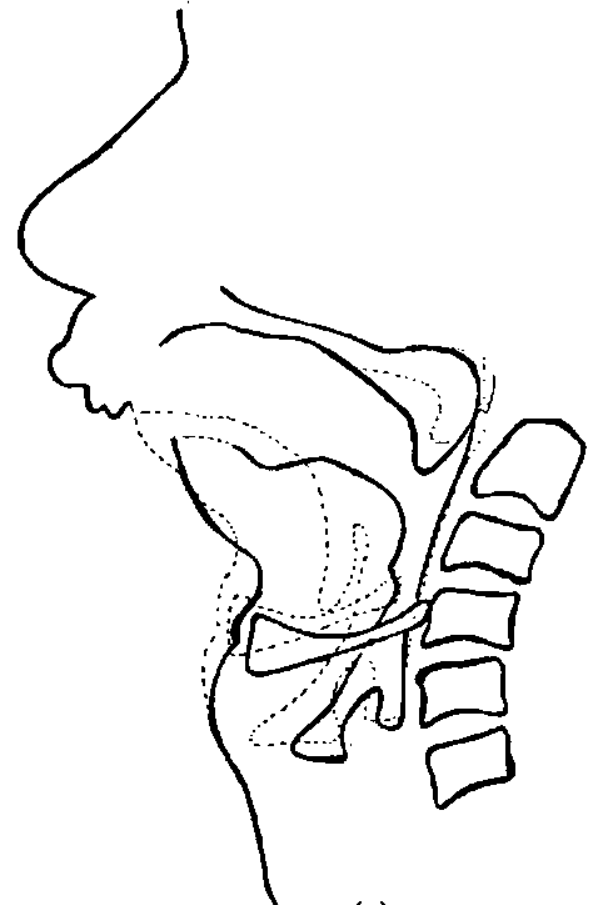

(a)

Pre-Reconstruction ।

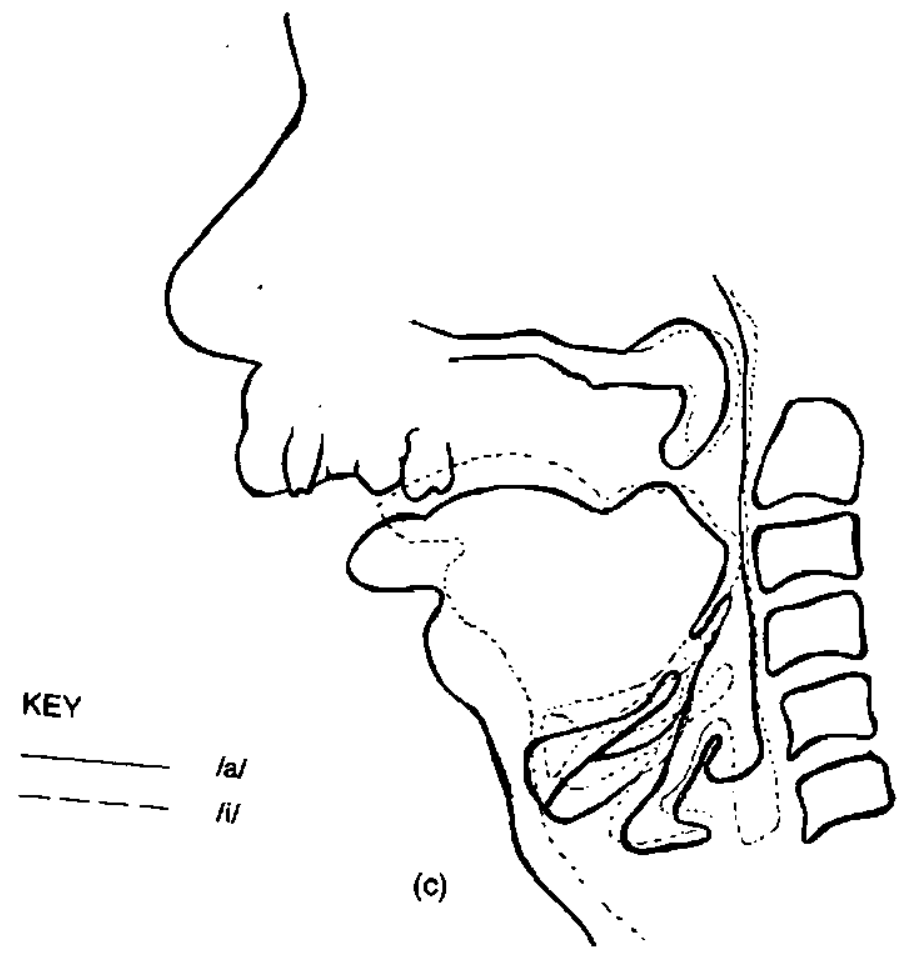

Pre-Reconstruction II

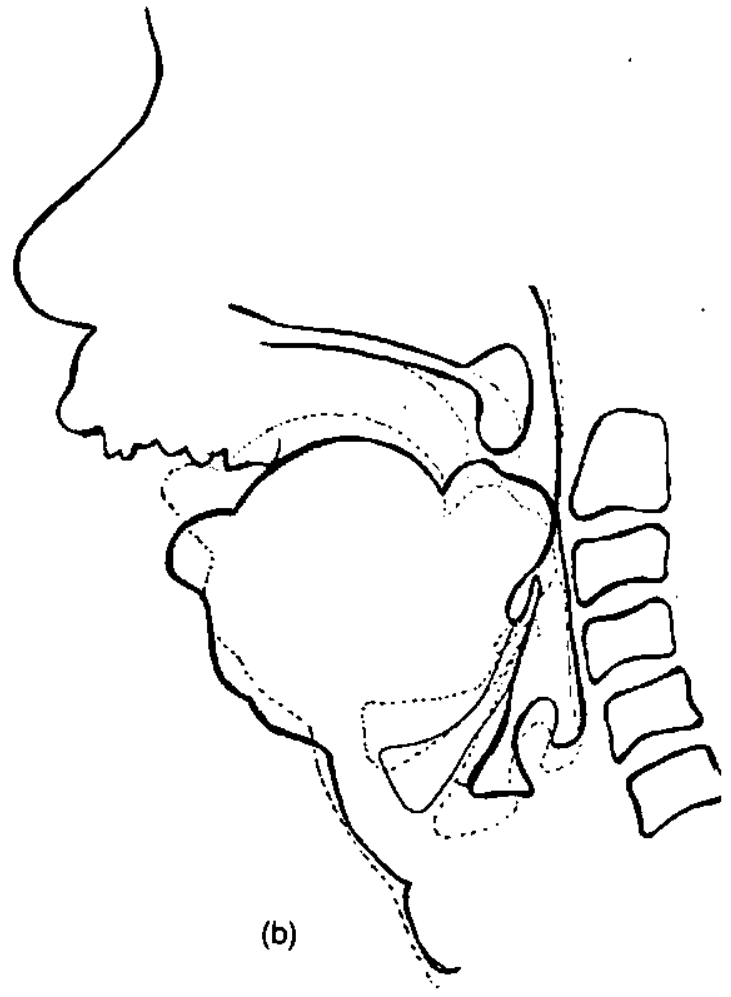

Post-Reconstruction I

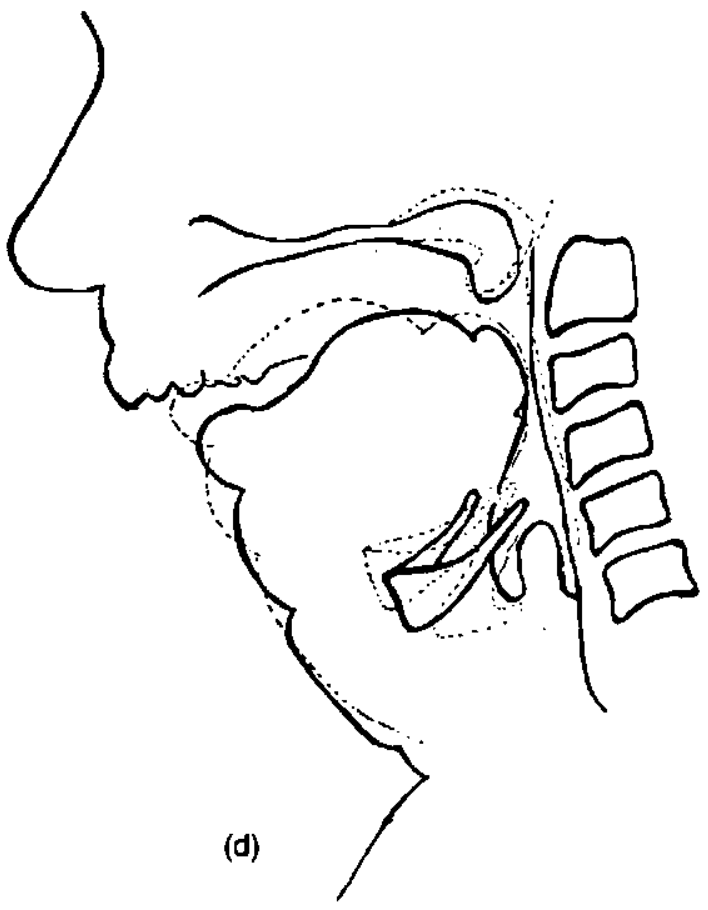

Post-Reconstruction II

Figure 5 Tracings of $/ \mathrm{a} / \mathrm{and} / \mathrm{i} / \mathrm{x}$ xerographs at four stages. Die Suid-Afrikaanse Tydskrif vir Kommunikasieafwykings, Vol. 30, 1983 

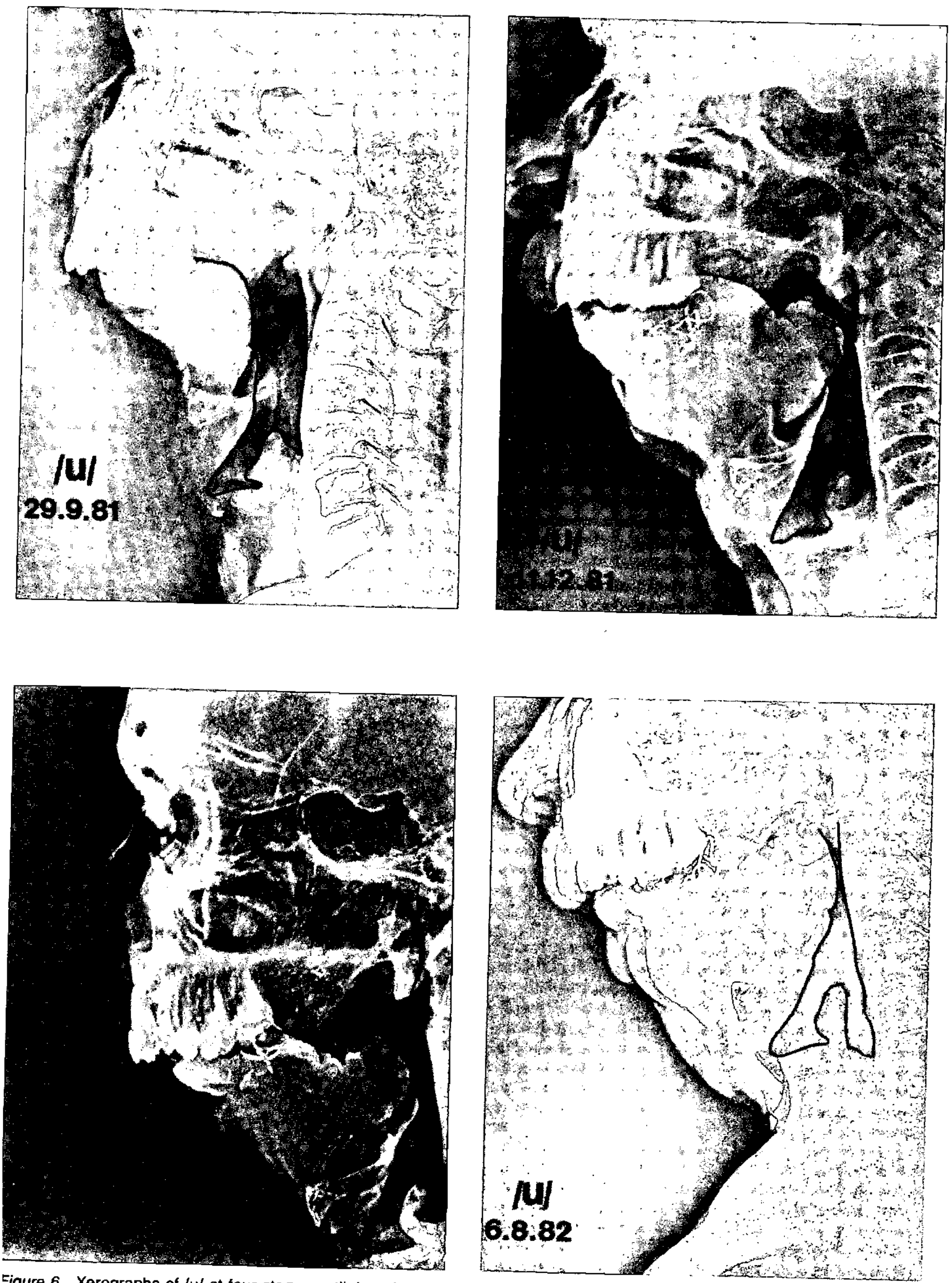

Figure 6 Xerographs of $/ u /$ at four stages outlining changes in vocal tract shape. 
variant gently rising convex formation, and the new appearance of a bump in the anterior oropharyngeal area can be observed. This was assumed to be a portion of the osteomyocutaneous flap. (See Fig. 6b.) The constancy of the dimensions of the oral and pharyngeal cavities can be observed. (Fig. 5b.)

3. Prior to the second reconstruction, the relative rigidity of the vocal tract can again be noted from the tracings. (Fig. 5c.) In particular, there is clearly narrowing of the pharynx compared to Pre-Reconstruction I. Comparison of the /u/ xerographs of Post-Reconstruction $I$ and PreReconstruction II, reveals slight shrinkage of the pharyngeal "bump" and the reduction in size of the gentle hump anteriorly when the graft had resorbed and atrophied.

4. Fiberoptic examination at this point, prior to Reconstruction II, revealed that the pharyngeal "bump" appeared to be the remnant of the tongue which had been sutured posteriorly in the erection of the island flap in the floor of the mouth area. In addition, this resulted in an extremely narrow airway. It would be expected that such a narrow communication between the pharyngeal and oral cavities would seriously affect the radiation of acoustic energy from the pharynx.

5. It was therefore recommended to the sulgeons undertaking the second reconstruction that the constriction in the pharynx be reduced and that the tongue remnant be repositioned anteriorly. This was performed unilaterally, as was evident from Post-Reconstruction II fiberoptic examination. Following this, it seemed that there was greater variability in the anterior floor of mouth height as seen on the tracings (Fig. 5d), although this feature is not wellillustrated on the / $u$ / xerograph following the second reconstruction, as the unilateral change is not captured. Hence the second reconstruction restored more open communication between the oral and pharyngeal cavities, allowing for radiation of sound out of the pharynx anteriorly through the vocial tract. Support for the notion of the significance to speech of the pharyngeal constriction and its subsequent reduction, is provided by the word in-

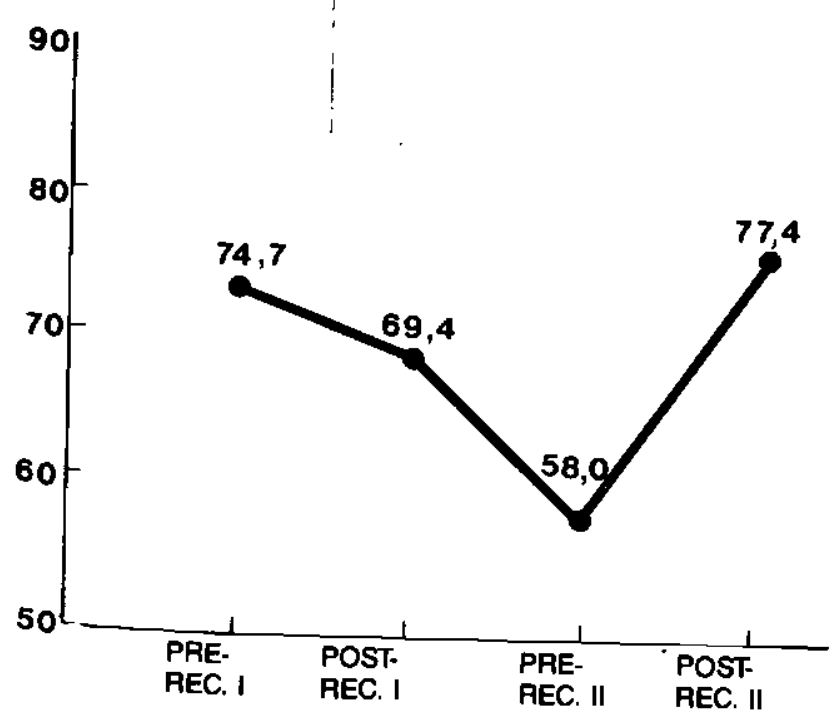

Figure 7 Percentage of intelligible vowels at each stage. telligibility results, where recognition of the subject's utterances varied in relation to the degree of constriction i.e. the greater the constriction, the lower the intelligibility, while the partially constricted pharynx resulted in improved intelligibility.

\section{VOWEL INTELLIGIBILITY}

The intelligibility of vowels was assessed by extracting the judges' imitations of vowels from their imitations of the stimulus words. Hence, vowel intelligibility was not examined in isolation, but, rather, in the context of words.

1. The effect of the first reconstruction was to reduce intelligibility, which deteriorated even further with atrophy of the graft.

2. Vowels were most intelligible following the second reconstruction, fractionally better than prior to any reconstruction (See Fig. 13). This result further substantiates the view that better radiation of acoustic energy was possible when the pharyngeal constriction was reduced.

3. The most intelligible vowel at all four stages was $/ a /$, possibly because the constriction was correctly positioned (i.e. back of the oral cavity) and of appropriate magnitude. (See Fig. 8.)

4. The back-rounded vowels $/ u /$ and $/ 0 /$ became more in telligible when the maxilla and replaced mandible were in better alignment, i.e. reconstruction was positive for the intelligibility of these phonemes. (See Fig. 8.)

5. Following the first reconstruction, /e/ deteriorated dramatically; possibly both the degree and position of constriction were totally inappropriate for its production.

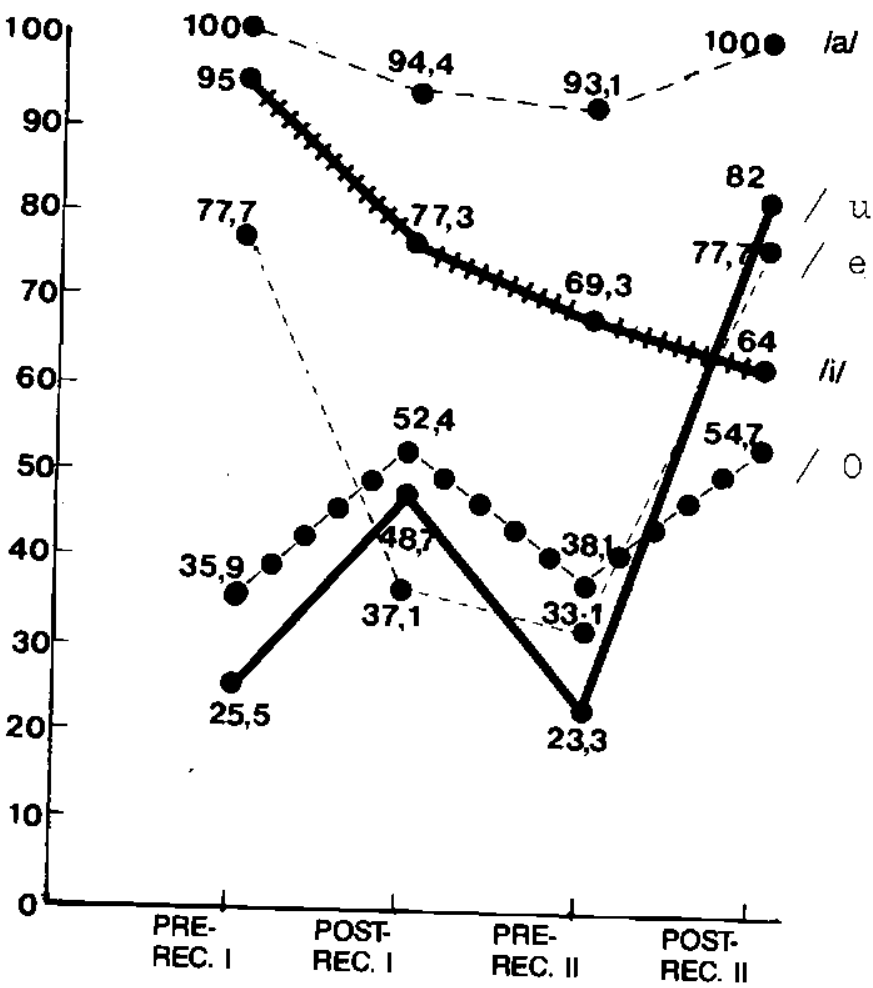

Figure 8 Percentage of individual vowel intelligibility at each stage. 
When the degree of constriction was reduced and sound allowed to radiate out of the pharynx, the previous level of intelligibility was restored.

6. The predominance of $/ a /$ substitutions for the mid-vowels /e/ and $/ 0 /$, was perhaps due to the position and degree of constriction, and the difficulty with explicit lip-rounding (because of absent sensation in the lower lip and poor maxilla-mandible alignment).

7. It appeared that when anterior constriction with the tongue remnant was possible (i.e. when the oral cavity was contracted, prior to any reconstruction), front vowels /i/ and /e/ were most intelligible while when there was the fixed posterior constriction due to the repositioned tongue remnant, the back vowels, $/ u /$ and $/ \mathrm{o} /$, became most intelligible. (See Fig. 13.) In other words, vowel intelligibility corresponded closely with the structure of the oral cavity.

Prior to any reconstruction, it seems that the vocal tract had some flexibility but limited ability to constrict at any point, so that it had the appearance of a single tube resonator, displaying free communication between the pharyngeal and oral cavities.

The effect of the first reconstruction was to introduce an extreme constriction, positionally invariant, with marginal communication between the two cavities.

The second reconstruction served to maintain an area of constriction even if it was positionally invariant and allowed for sufficient communication between the two cavities for radiation of acoustic energy throughout the vocal tract. These appear to be the critical factors in vowel intelligibility for this patient.

\section{E. CONSONANTS}

Generally, the trends in consonant perception were consistent throughout all four stages, but perception became more predictable and stereotyped, showing reduced variability during the intermediary two stages, i.e. a limited range of consonants was being perceived. (See Table 1.)

l. During the interim two stages, fewer consonants requiring an oral articulation were perceived i.e. most consonants were perceived as $/ 2 /$ and $/ \mathrm{h} /$ (glottal). When viewed in conjunction with the word intelligibility results, inaccuracy of consonants produced in the oral cavity seems preferable to glottal substitutes.

2. The judges attempted to simulate the muffled auditory impression of the voice by velarising, nasalising and pharyngealising i.e. by effecting a thoroughly atypical balance among the resonators, for the phonetics of the language.

\section{DISCUSSION}

The present study indicates that speech intelligibility was greatest prior to any reconstructive procedures. This level of intelligibility $(28,9 \%)$ corresponds fairly closely to the range of partial glossectomy pre-therapy speech intelligibility scores reported by Skelly et al., ${ }^{18}$ which ranged from $6-24 \%$. It is interesting that these authors used a similar test paradigm to that employed in the present study - they attempted to sample all the phonemes of the language, selected phonetically balanced word lists as stimulus items and administered pre-

Table 1 Patterns of Consonant Perception

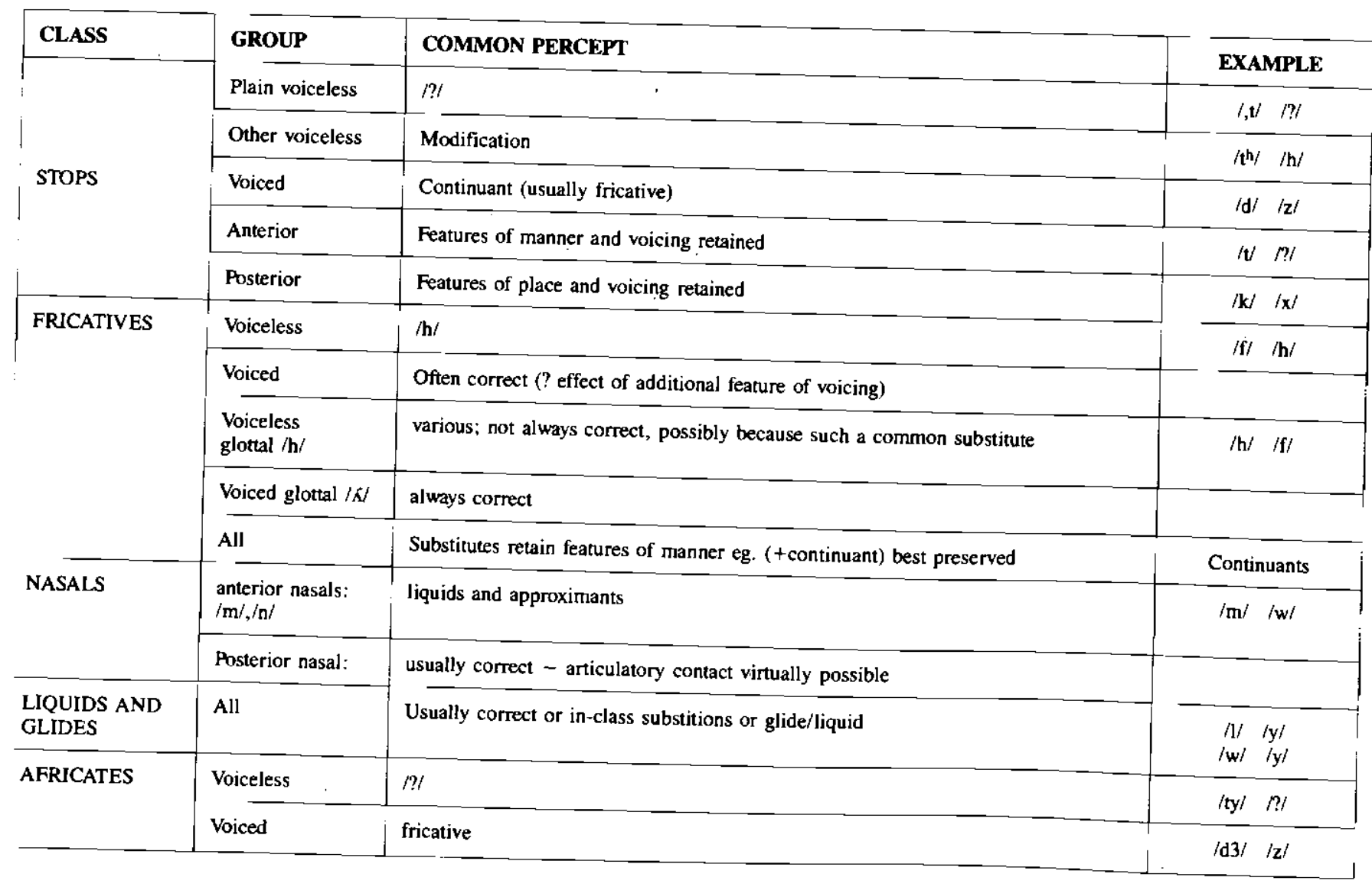


recorded stimuli within an open response format. In contrast, other studies; ${ }^{5.11 .12}$ have employed either multiple or forced choice paradigms (closed response formats) or utterances ranging in length and compexity, from nonsense syllables to sentences. ${ }^{11}$ 12. 20

The stimulus presentation employed in this study diverges from a representation of real verbal interaction, thereby undermining the patient's "functional intelligibility" because words were produced without any syntactic context and without the complementary visual modality, which allows for an integrated signal. ${ }^{15}$ Nonetheless, for the present purpose, this method was useful in describing the relationship between structure and function. In addition, some words e.g. "cija" did not have an initial vowel to provide acoustic cues in the form of formant transition. It also emerged that approximately five of the test words (asterisked in the word list) were not familiar to all the judges, and hence ought to be altered in future tests. Further, being presented in an imperfect form, therefore almost certainly inaccessible to passive vocabulary, these items may be regarded as "dead weight", 4 as they are not discriminating items. However a source of useful information to the judges was the fact that Nguni languages use tones phonemically. These tonemes are likely to have provided helpful suprasegmental cues to words, evident in the way the judges always reproduced the tone contours of the stimuli correctly.

Bloomer and Hawk' mention that $/ \mathrm{i}$ / is the least intelligible vowel phoneme for the glossectomee; however, in this case, combined glossectomy-mandibulectomy with mandibular retraction and inability to produce lip-rounding, appears to affect back vowels more dramatically, rendering these even less intelligible than anterior vowels. The nature of the maxillamandible relationship is as important to consonants as to vowels. If alignment is accurate and bilabial approximation achieved, the subject could be expected to produce good bilabial consonants $-/ \mathrm{p} /, / \mathrm{b} /, / \mathrm{m} /, / \mathrm{w} /$, - which may enhance intelligibility considerably. It is therefore critical for reconstructive surgery to strive to meet the goal of adequate maxillary-mandibular occlusion. Furthermore, for the glossectomee with an additional mandibulectomy, mandibular replacement would seem to be a crucial procedure to vowel and consonant intelligibility and one that is more than
"elective".

The distinctive predominance of the glottis as a compensatory articulatory site for a glossectomy-mandibulectomy patient is emphasised in this study, particularly in the case of stops and fricatives. The tendency of the judges to perceive most consonants as having a "fricative manner of production", and a "glottal place of articulation", best describes the compensatory phenomena associated with this subject. These are not cited as compensatory characteristics in the literature although mention is made of the compensatory use of mandibular, buc$\mathrm{cal}$, labial and palatal movements. ${ }^{18}$

However, the glottis as the site of compensatory articulation is not surprising as the larynx was the only point along the entire vocal tract where complete closure could be effected. Apresulting in was achieved at the lingua-velar junction resulting in partial intelligibility of the velar stops $/ \mathrm{k} /$ and $/ \mathrm{g} /$,
and the velar nasal $/ \mathrm{g} /$.

Die Suid-Afrikaanse Tydskrif vir Kommunikasieafwykings, Vol, 30, 1983
The trend that glides, liquids and nasals were clearer prior to reconstructive attempts, may have been due to better presurgical ability to constrict the oral cavity. Although the dissected muscles, namely, geniohyoid, mylohyoid and hyoglossus had probably atrophied following anterior tongue transection, the possibility of styloglossus having been intact, is not unlikely. Support for this notion is provided by the observation that high-back vowels and velar consonants were generally recognisable prior to any reconstruction. The presence of residual tongue stump mobility prior to reconstructive efforts, is implied.

La Riviere et al." propose that some spontaneous improvement of glossectomee speech occurs with time. This may be true for primary closure but not necessarily for surgical reconstruction using flaps which have the potential to resorb. In this case, partial contraction was a reality and altered the vocal tract dimensions considerably, with critical articulatory
and auditory effects.

The findings of this study underline the need for the speech therapist's involvement in the management of the oral cancer patient. The speech therapist may be active from the very early stages of pre-operative counselling, post-surgical communication and swallowing facilitation. He/she may later implement a communication board or gestural system, and could ultimately focus on "communication" (perhaps utilising augmentative methods to supplement the auditory signal)
rather than "speech".

This is a somewhat predictable conclusion. What this paper demonstrates most powerfully, however, is that speech may be a sensitive and valid criterion of the efficacy of surgical reconstruction. For too long, the role of the speech pathologist in this area has resided in dealing with a surgical fait accompli, and with the use of treatment strategies such as "vocal parameter manipulation" 19 and "compensatory physiologic phonetics". 18 The present writer suggests that there is a need for the speech therapist to enter the treatment arena at a point where he/she can be instrumental in determining and planning the "structural springboard" for therapy and assist in the creation of optimal prognostic potential. With a sound knowledge of speech anatomy and articulatory phonetics, the speech therapists's intervention may serve as the bridge between anatomical structure and functional integrity.

"The management of head and neck cancer presents a unique opportunity for the co-operative efforts of multiple disciplines in order to achieve both maximum cure rates and maximum
rehabilitation."zl

\section{ACKNOWLEDGEMENTS}

The writer wishes to thank Prof. A. Traill, Associate Professor, Department of Linguistics, University of the Witwatersrand, Johannesburg, for his assistance, guidance and time in conducting investigative procedures, constructing the intelligibility tapes and interpreting the data. The writer also wishes to thank Dr. Claire Penn, Lecturer, Department of Speech Pathology and Audiology, University of the Witwatersrand, for her helpful comments in the writing of this
article. 


\section{REFERENCES:}

1. Bloomer, A. H. and Hawk, A. M. (1973): Speech Considerations: Speech Disorders Associated with Ablative Surgery of the Face, Mouth and Pharynx - Ablative Approaches to Learning. In Orofacial Anomalies: Clinical and Research Implications. A.S.H.A. Reports 8 . Publication of the American Speech and Hearing Association, Washington.

2. Bradley, P. J., Hoover, L. A. and Stell, P. M. (1980): Articulation after Surgery to the Tongue. Folia Phoniatr. 32 334-341.

3. Crikelair, G. (1967): History of Reconstructive Surgery in Head and Neck Cancer. In Cancer. of the Head and Neck. Conley, J. (Ed.). Butterworthy Inc., Tennesee.

4. Egan, J. P. (1948): Articulation Testing Methods. Laryngoscope 58, 955-991.

5. Georgian, R. A., Logemann, J. A. and Fisher, H. B. (1982): Compensatory Articulation Patterns of a Surgically Treated Oral Cancer Patient. J. Speech Hear. Disord. 47, 154-159.

6. Hall Powers, M. (1971): Functional Disorders of Articulation - Symptomatology and Etiology. Chapter 33 in Handbook of Speech Pathology and Audiology. Travis, L. E. (Ed.). Prentice-Hall, New Jersey.

7. Holonger, P. H., Lutterbeck, E. F. and Bulger, R. (1972): Xeroradiography of the Larynx. Arch. Otolaryngol. 81, 806-808.

8. Isaacson, C. (1982): Pathology of a Black African Population. Springer-Verlag, Berlin, Heidelberg, New York.

9. Khumalo, S. J. M. Zulu Tonology (1981): Unpublished Dissertation. Submitted for the Degree of Master of Arts, University of the Witwatersrand, Johannesburg.

10. Lanham, L. W. (1969): Generative Phonology and the Analysis of Nguni Consonants. Lingua 24, 155-162.

11. La Riviere, C., Seilo, M. T. and Dimmick, K. C. (1974): The Pretherapy Speech Intelligibility of a Glossectomee. J. Commun. Disord. 7, 357-364.

12. La Riviere, C., Seilo, M. T. and Dimmick, K. C. (1975): Report on the Speech Intelligibility of a Glossectomee. Folia Phoniatr. 27, 201-214.

13. Leonard, R. and Gillis, R. (1982): Effects of a Prosthetic Tongue on Vowel Intelligibility and Food Management in a Patient with Total Glossectomy. J. Speech Hear. Disord. 47, 25-30.

14. Massengill, R., Maxwell, S. and Pickrell, K. (1970): An Analysis of Articulation Following Partial and Total Glossectomy. J. Speech Hear. Disord. 35, 170-173.

15. McCormick, B. (1979): Audio-visual Discrimination of Speech. Clin. Otolaryngol. 4, 355-362.

16. McDonald, E. T. (1964): Articulation Testing and Treatment: A Sensory Motor Approach. Stanwix House, Pittsburgh.

17. Myers, E. N. (1972): Reconstruction of the Oral Cavity. Otolaryngolgic Clinics of North America, 5, 413-433.
18. Skelly, M., Spector, D. J., Donaldson, R. C., Brodeur, A. and Paletta, F. X. (1971): Compensatory Physiologic Phonetics for the Glossectomee. J. Speech Hear. Disord. 36, 101-114.

19. Skelly, M., Donaldson, R. C., Fust, R. S. and Townsend, D. L. (1972): Changes in Phonatory Aspects of Glossectomee Speech through Vocal Parameter Manipulation. $J$. Speech Hear. Disord., 379-389.

20. Skelly, M. Glossectomee Speech Rehabilitation. (1973): Charles C. Thomas, Springfield, Illinois.

21. Southwick, H. W. (1973): Cancer of the Tongue. Surgical Clinics of North America 53, 147-158.

22. Summers, G. W. (1974): Physiologic Problems Following Ablative Surgery of the Head and Neck. Otolaryngologic Clinics of North America 7, 217-250.

23. Ziervogel, D., Louw, J. A. and Taljaard, P. C. (1981): $A$ Handbook of the Zulu Language. Third Edition. J. L. Van Schaik, Pretoria.

\section{APPENDIX}

\section{NGUNI SPEECH INTELLIGIBILITY WORD LIST}

1. umunwe (finger)

2. inqawe (a pipe)

3. ivovo (strainer)

4. ithanga (pumpkin)

5. itiye (tea)

6. incwadi (book)

7. inyoni (bird)

8. uzipho (finger-nail)

9. isichaka (poor fellow, servant)

10. ihashi (horse)

11. idada (duck)

12. ugogo (grandmother)

13. umhume (cave)

* 14. isipoliyane (female hysteria or a type of brain disease)

15. kaka (to excrete faeces or to surround)

16. khipha (take)

17. tshela (tell)

* 18. ukubhubha (to die)

* 19. ububovu (pus)

20. isifo (sickness)

21. rola

22. hlola

23. dlala

24. xhosa

25. cija

26. qangqa

27. inxele

28. iqhude

29. ingcawe

* 30. ingxoko

(to roll or to pay out) - Xhosa (inspect)

(play)

(chase away)

(sharpen)

(explain)

(left side)

(a cock)

(type of assegai)

(grain store)

*: Words not familiar to all three judges. 


\section{GSI 28 Auto Tymp}

The GSI 28 AUTO TYMP provides testing capability for tympanometry, ipsilateral and contralateral acoustic reflex testing and screening audiometry. Selection of test sequence is as simple as pressing a button! The Auto Tymp is lightweight and compact so it can be easily moved from one location to another. An optional carrying case is available if more portability is required.
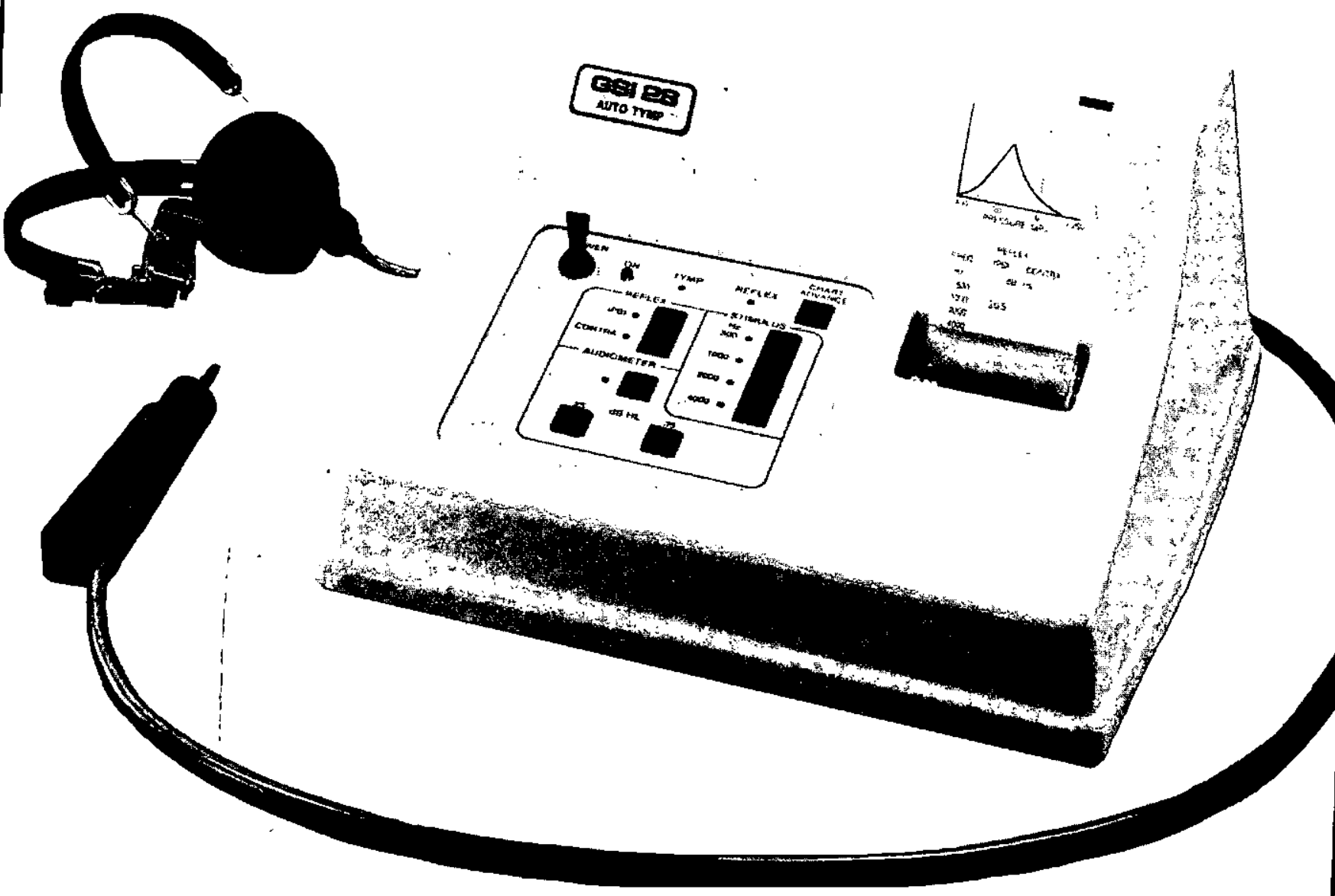

The Needier Westdene Organisation (Pty) Limited

In association with / In medewerking met

HEARING AND ACOUSTIC INSTRUMENTS (PTY) LTD

LEWIS'S HEARING CENTRE (PTY) LTD

ENGINEERED ACOUSTIC PRODUCTS

NOISE CONTROL

Needler Westdene House, 33 Durham St., Raedene, Johannesburg 2192, South Africa. Telex: 4-25028.

P.O. Box 28975, Sandringham 2131, South Africa. Tel: (011) 640-5017. Cables: Needlerog. 